\title{
The Impact of Learner Violence in Rural South African Schools
}

\author{
G. D. Singh ${ }^{1}$ and Trudie Steyn $^{2 *}$ \\ ${ }^{1}$ Empangeni, KwaZulu-Natal \\ ${ }^{2}$ University of South Africa, Department of Educational Leaders and Management \\ ${ }^{2}$ E-mail: Steyngm1@unisa.ac.za
}

\author{
KEYWORDS Learner Aggression. Victims. Unsafe Schools. Psychological Impact
}

\begin{abstract}
A safe school environment is central to learners' academic performance and holistic development. This article reports on part of a study that sought to identify the forms of learner aggression, the contributory factors to aggression, the consequences and psychological effects of learner aggression and the identification of strategies that can help to manage learner aggression in rural secondary schools in the Empangeni district of KwaZulu-Natal. A qualitative research design was deemed to be most appropriate for the purpose of this study and interviews were conducted with principals, teachers and students in the selected schools. The findings identify a number of psychological responses of victims to learner aggression and the consequences of learner aggression in schools, which have had a negative impact on the quality of teaching and learning in these schools. This research concluded that the consequences of learner aggression are devastating, have a serious effect on the victims mental health and leads to high levels of stress, anxiety, depression and even suicide.
\end{abstract}

\section{INTRODUCTION}

The frequent occurrence of aggressive and violent behaviour displayed by learners in schools has had a devastating effect on the school system and has become a cause for great concern among the stakeholders involved in the South African school system (Bester and Du Plessis 2010; Gasa 2012). The violent acts perpetrated by aggressive youth impact negatively on the ethos of the school, compromise the safety of learners and educators, which in turn, affects teaching and learning adversely in the classroom (Anderson 2007; Naran 2006). Bester and Du Plessis (2010) in particular called for more studies to be conducted on learner aggression in order to understand the problem and to provide solutions to curb the problem in schools.

A study by the South African Institute of Race Relations in 2008 found that South African schools are the most dangerous in the world (Blaser 2008). In that study, South African school learners were asked whether they felt safe at school and whether they had experienced incidences of bullying directly or indirectly in their class within a four-week study period. Their responses were startling. Only $23 \%$ of South African learners reported that they felt safe at school (Blaser 2008).

The rural Empangeni district in KwaZuluNatal, where this research was undertaken, is no different. High incidences of learner aggression have provided the spark for many instances of learner violence in schools. For years, both teachers and learners have been confronted by incidents of violent behaviour in their schools. In this regard, the local print media have reported on numerous incidents of abuse, crime and violence stemming from learner aggression in schools. In addition, the widespread use of drugs and alcohol on the school premises during school hours and the use of weapons by learners to force teachers and innocent learners into submission is a serious cause for concern. Learner violence militates against the provision of a safe school environment in which effective teaching and learning can take place. Irrespective of its origin, violence emanating from learner aggression has catastrophic and dire consequences for teachers, parents and students in particular. In attempting to reduce aggressive behaviour in schools, it is pivotal to understand certain aspects of learner aggression. The purpose of this article is to outline the impact of learner violence. It also attempts to analyse the psychological harm done to the victims of learner violence and to explain the conse-quences of learner violence on victims in schools.

\section{Theoretical Framework}

Various theories relating to learner violence and/or aggression were used to interpret the findings of the study. The relevance of these theories become clearer when discussed in the context of the findings later in this research paper.

Bandura's social cognitive theory (1962) maintains that depressed people not only judge 
themselves ruthlessly, but also tend to treat themselves roughly for their inadequacies, resulting in feelings of worthlessness, chronic misery, pervasive depression and a lack of purpose (Feist and Feist 2009). The behavioural theory emphasises the learning of aggression in a social context (Moeller 2001). A psychological disturbance results when either feelings of threat or fear persistently prevent a person from feeling secure, and when evidence of the untrustworthiness of others becomes overwhelming, the result is a relatively permanent and debilitating feeling of anxiety and tension (Feist and Feist 2009). Mowrer's 1960 two-factor theory of phobia development cited in Du et al. (2008) suggests that excessive fear is the result of a direct conditioning experience and its maintenance by avoidant behaviour. In terms of Kelly's construct theory (1950), which concurs with the above, fear arises when a new construct is about to enter the person's construct system (Olatunji and Lohr 2004). Olatunji and Lohr (2004). According to Kelly, cited in Olatunji and Lohr (2004), a person who cannot manage threatening events experiences great distress.

Beck's cognitive theory of anger (1976) cited in Olatunji and Lohr (2004), shows that strong emotions lead to negative experiences that exist in a continuum in which the intensity, frequency and duration of the experience result in impairment of the cognitive. Since frustration plays a meaningful role in students' aggression, Dollard's 1939 frustration-aggression theory is also applied (Bandura 1973). According to this theory, learners are encouraged to behave with aggression through a frustration-produced drive; aggressive energy is created when learners are frustrated by their negative personal circumstances and this energy activates dominant aggressive responses (Bandura 1973).

Carl Rogers's person-centred theory (1951) is also considered as it postulates that individuals behave in ways that are congruent with their concepts of self (Pervin and Cervone 2010). People with low self-esteem have the tendency of maintaining a poor self-image which leads to the experience of negative emotions. Ancer (2009) agrees with the theory by stating that the victims of aggression tend to have low selfesteem, are anxious, fearful and passive and struggle to assert themselves. This is also in keeping with Kelly's construct theory which states that fear occurs when a new construct is about to enter a person's construct system and as a result of the person's inability to manage threatening events, the person experiences great distress (Pervin and Cervone 2010).

According to Shaffer and Kipp (2010), elevated levels of stress are major contributors to the negative effect of aggression on adolescents who become seriously depressed, are constantly "down" and as a result may become suicidal. In this regard, Durkheim's theory of suicide (1897) was used to explain why students commit suicide. The theory views suicide as a phenomenon that arises from societal pressures and influences (Holmes and Holmes 2005: 27). Durkheim cited in Holmes and Holmes (2005) points out that social forces increase a person's probability of committing suicide.

\section{Literature Review}

Aggressive and violent behaviour is any form of behaviour designed to harm or injure a living being, who in turn, is motivated to avoid such behaviour (Shaffer and Kipp 2010). Various factors play a critical role in causing violence in schools. These may include biological, family, school and environmental factors. For the purpose of this study, this section briefly highlights the characteristics and consequences of learner violence.

The psychological harm that occurs in an environment plagued by violence should not be underestimated (Bemak and Keys 2000). The many and varied characteristics of learner violence are highlighted in the sections below. Characteristics of learner violence

\section{Hyperactivity}

Violent and aggressive learners tend to find it difficult to sit still and often use their energy to disrupt class lessons, move around the class indiscriminately and disturb their classmates during the teaching and learning process. Hyperaggressive children are most likely to suffer from a concentration disorder and have difficulty maintaining the required level of attention for extended periods (Delfos 2004). The consequences of these types of behaviour are lower academic achievement, more school expulsions, more antisocial behaviour, more substance abuse, a poorer occupational adjustment, more 
parent and teacher hostility and higher levels of delinquency (Moeller 2001). In effect, most hyperactive children tend to be non-compliant, defiant, easily distracted and extremely temperamental (Moeller 2001).

\section{Temperament}

Children with a difficult temperament, that is, children who have a bad temper or are generally moody, have trouble responding to new situations, resist change and react to new stimuli with shock or rejection (Delfos 2004). This type of difficult temperament is often the precursor of conduct disorders during youth when children display heightened irritability and react angrily at the slightest provocation through acts of physical and verbal aggression. Learners who are prone to violent and aggressive behaviour generally experience a broad range of maladaptive behaviours (Bemak and Keys 2000). According to Moeller (2001), children with difficult temperaments are more at risk of developing serious behaviour problems, such as bullying, later during adolescence.

\section{Bullying}

The word "bullying" refers to a social process in which an adolescent exerts power or influence over another student in a negative manner in order to achieve a desired effect or outcome (Jenson and Dieterich 2009). Bullying occurs in physical, social and emotional contexts and varies considerably in severity. It occurs when a more powerful person directs his/ her aggression repeatedly at a less powerful person. It can be verbal, physical or social and has the intention to hurt, humiliate and isolate individuals (Ancer 2009). It also occurs through the electronic media (cyber-bullying), in the form of harassing or threatening text messages on cell phones, emails and instant messages (Shaffer and Kipp 2010).

Victimised children are at risk of developing a variety of adjustment problems, including loneliness, anxiety, depression, further erosion of self-esteem and a growing dislike for and avoidance of school (Shaffer and Kipp 2010). The most devastating long-term effect of bullying, however, is suicide (Moeller 2001). Bullies manifest antisocial violent behaviour in the form of physical, verbal and sexual aggression (Carter 2006).

\section{Physical, Verbal and Sexual Aggression and Violence}

\section{Physical Aggression and Violence}

Physical aggression and violence include acts such as hitting, kicking, stabbing, shooting, pushing and shoving others, throwing objects, breaking windows, defacing property and setting objects alight (Moeller 2001). Retaliation because of provocation and bullying at school are further contributory factors leading to violence (Bester and Du Plessis 2010: 209). In addition, factors such as alcohol use, gangsterism, gambling and prejudiced behaviour play a significant role in promoting physical aggression among secondary school students. Harsh language and bullying are types of behaviour viewed as precursors to physical violence (Marsh et al. 2009). Physical violence and bullying may affect the learning environment in the school and have a direct impact on the quality of education (Marsh et al. 2009).

\section{Verbal Aggression and Violence}

Verbal aggression and violence can involve behaviour such as making threats or writing threatening notes or letters, calling names, spreading gossip and teasing others (Moeller 2001). Girls are more inclined to make use of verbal and indirect aggression than boys (Smit 2003). They are more likely than boys to display covert forms of hostility towards others by snubbing or ignoring them or by trying to undermine their relationships or social status (Shaffer and Kipp 2010). Verbal threats of aggression can be just as damaging as physical violence.

\section{Sexual Aggression and Violence}

Sexual aggression and violence are expressed in sexualised verbal bantering and the sexual abuse of victims (Carter 2006). Boys also express their sexual frustrations by violating rules and writing pornographic graffiti with inappropriate language on school walls, in toilets and in public places (Moeller 2001). Moreover, they sometimes use sexual bantering to embarrass girls or to humiliate them after being rejected by girls. When teenage boys' advances are rejected by girls, they tend to express their anger 
and frustrations indirectly through acts such as substance abuse and sexual misconduct (Shaffer and Kipp 2010). In turn, because the boys' sexual slurs are aimed at hurting them, girls may retaliate by calling the boys "dick head," "poof" or "gay" (Mabitla 2006: 35). Girls manifest sexual aggression by wearing sophisticated make-up, colouring and styling their hair, shortening their skirts and wearing tattoos to gain boys' attention (Mabitla 2006).

\section{Vandalism and Arson}

School vandals are likely to be youngsters between the ages of 11 and 16 who are chronically suspended or who play truant (Finn and Frone 2003). Both interpersonal aggression and vandalism at school were more likely to occur among learners who have rebellious personality characteristics and learners with poor school achievement (Finn and Frone 2003). Damaging buildings and defacing them with paint (graffiti) can be an expression of resisting authority (Delfos 2004). Committing acts of vandalism may be the aggressive learners' way of gaining attention because of the low self-esteem they experience (Ancer 2009).

\section{Low Self- esteem}

Studies support the view that low self-esteem is related to antisocial and violent behaviour among secondary school students (Moeller 2001). Learners with low self-esteem are unable to gain recognition from others in socially conventional ways such as through academic activities, sport or extracurricular activities. Anxious, insecure and frustrated with their inability to gain needed recognition, these learners resort to anti-social and aggressive behaviour in order to gain recognition and feel better about themselves (Moeller 2001).

However, the victims of violent behaviour suffer feelings of anxiety, insecurity and fear (Dellasega and Nixon 2003). Feelings of inferiority and guilt may cause loss of self-esteem and predispose youngsters to depression and suicidal tendencies (Moeller 2001). These learners' inability to cope with the injustice, helplessness and hopelessness of their situations results in them repressing their feelings and expressing antisocial behaviour in the form of absenteeism, reclusiveness and substance abuse. Skipping classes or staying at home for fear of being bul- lied at school leads to academic underachievement where the learner falls behind in his/her assignments, homework, tests and assessments (Bemak and Keys 2000). Learners who are insecure and who experience social isolation because of low self-esteem are prone to academic underachievement (Bemak and Keys 2000).

\section{Underachievement}

One of the best-documented facts about antisocial and violent learners is that they do not perform well at school (Bester and Du Plessis 2010; Moeller 2001). Learners with poor academic skills become frustrated, lose academic motivation and as a result, eventually resort to antisocial and violent behaviour. As they constantly experience failure because of concentration, violent learners become envious of their peers' success (Bemak and Keys 2000: 8) and as a result they become easily bored, disrupt lessons, play truant, join deviant peers, harass other students and become delinquents (Moeller 2001).

Various factors contribute significantly to underachievement of both learners and teachers at school, the consequences of which are prolonged absenteeism, frequent resignations and even death caused by stress, anxiety and depression (Makwabe 2007).

\section{Consequences of Learner Violence}

Research findings indicate that for every violent act perpetrated by an aggressive learner, there is a consequence that not only affects the victim adversely, but also the entire school community (Huston and Ripke 2006). Accordingly, teachers who are concerned about their safety are less able to focus on teaching and, likewise, learners who worry about being safe are less able to concentrate, are less confident and suffer low self-esteem.

\section{Low Self-esteem}

Victims of violent behaviour suffer feelings of anxiety, insecurity and fear (Dellasega and Nixon 2003). Feelings of inferiority and guilt may cause loss of self-esteem and predispose learners to depression and suicidal tendencies (Moeller 2001). These learners' inability to cope with the injustice, helplessness and hopelessness of their situations results in them repress- 
ing their feelings and expressing antisocial behaviour in the form of absenteeism, reclusiveness and substance abuse. Skipping classes or staying at home for fear of being bullied at school leads to academic underachievement where learners fall behind in their assignments, homework, tests and assessments (Bemak and Key 2000). Learners and teachers who become insecure and suffer low self-esteem because of learner violence are prone to absenteeism, resignations, transfers and even death.

\section{Absenteeism, Resignations and Death}

Learners, teachers and management staff may experience intimidation and fear at school (Bemak and Keys 2000: 11). It is not uncommon for affected learners to skip lunch or avoid the use of the school toilets for the entire school day out of fear of confrontation. In more extreme instances, learners absent themselves from school in order to minimise stress. Importantly, prolonged absenteeism is detrimental to the learners' progress as he/she falls further and further behind academically (Bemak and Keys 2000).

Teachers who feel vulnerable themselves are less likely to provide additional services, for fear of intimidation, preferring instead to retreat from the "war zone" as quickly as possible at the end of the school day (Bemak and Keys 2000). Accordingly, affected teachers tend to take long periods of leave from school because of stressrelated problems, and this prolonged absenteeism affects teaching and learning adversely at school.

According to the report of the South African Human Resources Commission, teachers are resigning from their jobs in large numbers because of the psychological and physical violence perpetrated on them by learners (Dibetle 2008). In some instances, it has escalated into fatalities, where teachers and learners have died at the hands of aggressive learners. Furthermore, the high levels of stress caused by school-based violence can result in teachers becoming depressed and being absent from school for days on end because of ill-health (Dibetle 2008).

\section{Ill-health}

The victims of violent acts often cannot cope with the resulting stress, anguish and humilia- tion (Carter 2006). According to Rigby (2002), such victims may suffer from poor health because of their inability to cope with the harassment, nastiness and constant victimisation. Undoubtedly, the aggressive behaviour displayed by violent youth can affect children mentally, psychologically and physically, most notably through the emergence of a post-traumatic stress disorder (Moeller 2001). The consequences of ill-health in learners affected by violence can be devastating to the extent that learners can suffer depression, which can eventually lead to suicide (Shaffer and Kipp 2010).

\section{Depression and Suicide}

Moeller (2001) confirms that depressed learners exhibit signs of intense unhappiness, intense irritability, and lack of interest or pleasure in activities such as eating, sleeping and motor activity. Since depression is a psychiatric disorder, it is accompanied by symptoms such as persistent feelings of hopelessness, and sometimes even suicidal tendencies. According to Shaffer and Kipp (2010), elevated levels of stress are major contributors to the negative effects on learners who become seriously depressed. These learners are constantly in a state of depression and despondency and their depressed states may eventually lead to suicide.

\section{RESEARCH DESIGN}

\section{Empirical Investigation}

A qualitative research design was deemed most appropriate to ascertain learners' psychological responses to violence and the consequences of learner violence since such a design is concerned with understanding a social phenomenon, that is, learner violence, from participants' perspectives (McMillan and Schumacher 2006).

The study was conducted in five rural secondary schools in the Empangeni district, KwaZulu-Natal, where the problem of learner aggression has manifested itself to a large extent. Two of the schools were deep rural schools with poor infrastructure, under resourced with no specialist rooms or computer centres. The other three schools were semi-rural township schools that had a relatively good infrastructure with specialist rooms including computer cen- 
tres. However, it was observed that in all five schools, sports facilities were severely lacking. All five schools served predominantly poor communities. The participants consisted of eight learners from the Representative Council of Learners (for the focus group), eight teachers (for the focus group) and the principals (for individual interviews) from each of the five schools. In total, five principals, 38 teachers and 40 learners participated in the interviews.

Semi-structured interviews were conducted with principals, while focus group interviews were conducted with teachers and learners from the selected schools to understand their perspectives on the impact of learner violence on their lives. All interviews were recorded, transcribed verbatim and analysed. Qualitative data analysis, which is primarily a systematic, inductive process of coding, categorising and interpreting the data, was used (McMillan and Schumacher 2006: 364). To make sense of the large volume of information, the collected data were organised into categories and subcategories.

The Research Directorate of the KwaZuluNatal Department of Education and the principals of the schools granted the researcher permission to enter their premises to conduct the study. Likewise, informed consent from all the participants (principals, teachers and learners) to participate in the study was obtained in writing, after having informed them of its purpose, the procedure to be followed, the risks, benefits and the measures implemented to ensure confidentiality (Johnson and Christensen 2011). Participants were informed in writing that their participation was voluntary and that interviews would be conducted with their consent or that of their parents and with prior arrangements with the principal of the school. They were informed that their responses would be tape-recorded and they granted their permission to do so in writing before the commencement of the interview.

Lincoln and Guba's model cited in Poggenpoel (1998) was used to ensure the trustworthiness of qualitative data. To maintain credibility, the empirical aspect of the study was done over a lengthy period, of approximately four months, and the information gleaned from all the participants was recorded and analysed accurately. Applicability (Poggenpoel 1998) was assured by providing sufficient descriptive in- formation in this study that could be of use in future research. In order to ensure dependability (Poggenpoel 1998), the study accounted for variables, which could possibly cause changes owing to the emergent nature of the design. To achieve confirmability (Poggenpoel 1998), member checking was done which means that the transcribed data were submitted to the participants to double-check that all the transcripts of the interview with each individual was authentic and accurately recorded. The over-arching questions in the study were:

- What were the characteristics of learner violence in rural secondary schools?

- What were the consequences and psychological impact of learner violence in rural secondary schools?

\section{FINDINGS AND DISCUSSION}

Owing to the wealth of information gleaned from participants, only the most important data are presented.

\section{The Psychological Effects of Learner Violence}

This study revealed a number of psychological effects of learner violence on students and teachers who are victims of violence, in particular low self-esteem, low morale and lack of confidence when they were bullied or humiliated. These findings were supported by Myburgh and Poggenpoel (2009) who report that learners experience negative feelings resulting from student violence, such as anger, worthlessness, humiliation, disappointment, discouraged feelings, depression and fear.

\section{Low Self-esteem}

Learners who are victims of violence tend to have certain characteristics in common, such as they often have low self-esteem, may be anxious and passive and struggle to assert themselves (Ancer 2009). Participants agreed that learner violence had a huge impact on the selfesteem of victims. Learners' inability to cope with the helplessness and injustice of their circumstances resulted in them repressing their feelings. The principal of School A explained how the victims of violence were affected: "They [learners] suffer from low self-esteem 
and their confidence is dented in a huge way". A similar sentiment was expressed when teachers were the victims as explained by the principal of School E:

... when teachers are affected by aggression ... they feel very small and they sometimes feel they should not continue teaching with that class. Once a teacher is offended by a very small boy, small girl - he doesn't feel proud of being the class teacher ... when the learner becomes aggressive with the teacher, other learners simply laugh and the teacher's image is now damaged.

Anderson (2007: 14) believes that adolescents have a fragile perception of themselves, which explains why learners who become victims of violence lose a sense of who they are. Moreover, for adolescents the need to belong to a group is paramount, and when they are victimised, this feeling of belonging is taken away from them (Anderson 2007). For the victims of bullying, the consequences are devastating (Shaffer and Kipp 2010) since it leads to a variety of adjustment problems, including loneliness, anxiety, depression, further erosion of self-esteem and a growing dislike for and avoidance of school (Moeller 2001; Myburgh and Poggenpoel 2009; Shaffer and Kipp 2010).

\section{Low Morale}

According to Bester and Du Plessis (2010), violence seems to be rising in schools and increasingly more violence is directed at educators than before. Teachers in this study expressed concern about the violence and its effect on their morale. In this regard, a teacher in School B said that violence "has affected teachers in such a way that our morale is at an all-time low." Another teacher (School B) added: “... low morale has led to low productivity in the classroom and ... I think that is a severe ... serious cause of learner aggression at our school." This is in keeping with the view espoused by Balt (2008) who maintains that aggression and violence perpetrated by learners at school contributed to the low staff morale. In other instances, as shown above, violence in schools was caused by the low morale of the staff. Bester and Du Plessis (2010) confirm that learner violence leads to a lack of teacher motivation to support students in the classroom.

\section{Lack of Confidence}

The teachers and principals agreed that the low morale of teachers resulted in a lack of confidence among teachers. The principal of School E stated the following: "They [the teachers] feel very small. Once a teacher is offended by a very small boy, small girl ... his image is now damaged." The principal of School A expressed a similar view about student violence: “... their [the teachers'] confidence is way down ... and it then becomes difficult to work with them [teachers] ... even their concentration level in class becomes so low." A teacher (School C) concurred with this viewpoint by stating that it demotivated teachers when learners" abused an educator". This view was echoed by a teacher in School D: "It kind of de-motivates a teacher to go back to the class and teach that class."

The above statements pertaining to the low self-esteem, low morale and lack of confidence exhibited by victims of violence support Carl Rogers's person-centred theory cited in Pervin and Cervone (2010), which postulates that individuals behave in ways that are congruent with their self-concepts. When victims suffer from low self-esteem, their lack of confidence inhibits their drive and enthusiasm to perform. Ancer (2009) and Bester and Du Plessis (2010) agree with this theory by asserting that victims of violence tend to have particular characteristics in common; they often have low self-esteem, may be passive and anxious and struggle to assert themselves. Moreover, this is also in line with Kelly's construct theory that declares that fear occurs when a new construct is about to enter a person's construct system and as a result of the person's inability to manage threatening events, the person experiences great distress (Pervin and Cervone 2010). Weingarten (2003) believes that learners who face aggression have feelings of worthlessness and a lowering of their self-esteem.

Poor self-esteem, low morale and a lack of confidence in oneself can result in feelings of insecurity, which ultimately leads to fear and anxiety.

\section{Fear and Anxiety}

According to Dellasega and Nixon (2003) and Myburgh and Poggenpoel (2009), the vic- 
tims of violent behaviour suffer feelings of anxiety, insecurity and fear. This was confirmed by one of the principals (School D):

Coming to school becomes fearful ... they fear coming to school because we also have cases of intimidation ... yes ... so students who are aggressive will intimidate those who want to come to school. So it results in fear and intimidation.

Teachers and learners also mentioned experiencing fear because of the threatening attitudes and behaviour of aggressive students. They also indicated that some teachers had resigned from schools as a result or their fear.

A student in School A expressed her views about being afraid:

This boy stood up and said [to us]"If anyone submits their homework, right now he will hit everyone'... because he didn't do his homework. Then the teacher said whoever does not submit their homework, she's 'gonna' take them to the office and I was scared to go to the office and I was also scared of being beaten by the boy.

The findings confirmed that being fearful and anxious continually led to a state of nervousness and heightened tension on the part of the victims of violence. This is also in line with the findings of Bester and Du Plessis (2010) who identified the following emotional responses to learner aggression and violence: fear, low selfworth and feelings of immense guilt in the way they are responding to such learner behaviour.

\section{Nervousness and Tension}

Participants reported that learner violence resulted in nervousness and tension of both teachers and learners, as a learner in School E explained:

Teachers as well as the learners, they may be discouraged in doing their work and they are afraid to commit themselves with a learner that is aggressive. It will be impossible to work together in groups with such a learner and they will feel nervous, they will become tense in that the learner may do bad things towards them.

The principal of School A concurred as follows with the above view:

The whole atmosphere changes, it becomes much more tense after this whole exercise [aggression situation]. You find that nobody is at ease; the teacher is not able to do his duties in a way that would please everyone.
It follows that because learners and teachers are nervous and tense they inevitably experience feelings of humiliation.

\section{Feelings of Humiliation}

The findings proved conclusively that feelings of humiliation and hopelessness in the victims surfaced after a violent act had been committed as indicated in these responses: the teachers felt "embarrassed", "traumatised" and "refused to work". One principal (School A) explained this as follows:

Performance is largely affected ... that is both the teacher's and the learners'... the teacher just gets fed up... tears will then take over because ... I mean we are all human beings at the end of the day.

One teacher at School $\mathrm{C}$ also highlighted the effect of violent and aggressive learners on teachers:

What they [violent and aggressive learners] also do is that they say: "Oh ... we can make this teacher cry now," so every time if you don't want a certain subject, "Let's make her cry and let's make her feel uncomfortable and then we get our free period" just to disrupt, stop the lesson.

A student at School A related a similar incident of assault on a teacher:

When the teacher told him [the learner] he must stop making noise and start doing his work, he started having a mouth (back-talking) with the teacher and the teacher began getting offended by the words because he started using offensive words and he started swearing. So this boy in grade nine actually started fighting with the teacher physically and took the teacher down on the floor and started hitting him ... he was affected dramatically.

The findings of this study are in line with those of Bester and Du Plessis (2010) who reported that teachers were hurt, and felt helpless and disillusioned when they experienced student violence. The research findings are also in keeping with the behavioural theory and the twofactor theory of phobia development where simple exposure to the cues associated with an intensely aversive event, can cause a person to become fearful, nervous and anxious about those cues (Feist and Feist 2009). In terms of Kelly's construct theory, which concurs with the above, fear occurs when a new construct is about to 
enter the person's construct system. According to Kelly, a person who cannot manage threatening events experiences great distress. From the above expositions, it is clear that violent behaviour on the part of attackers provides the stimulus for a conditioned response of avoidant behaviour in victims who react by being fearful and anxious to the extent that they avoid the attackers by absenting themselves from school or quitting school altogether. It was evident that teachers were too scared to teach in these schools. Because of this fear, many suffered from depression and absented themselves from school for lengthy periods.

\section{Depression}

Learner violence often leads to a feeling of depression among victims (Myburgh and Poggenpoel 2009), which this study underscores. Educators absented themselves from school because of pressure in the class and the trauma and depression they suffered, while student violence depressed many victimised learners and made them scared. Regarding educator depression, the principal of School D contended: "I've got a lot of medical certificates which say this educator cannot work because of depression". The principal of School C elaborated as follows on the issue of depression:

It's a scary thing: learners tend to stay at home ... teachers stay at home ... or they might just put in sick leave ... psychological leave... depression leave. A lot of teachers take depression leave because they can't handle the discipline in high schools.

The above statements support Bandura's social cognitive theory, which contends that failure frequently leads to depression, and depressed people often undervalue their own accomplishments (Feist and Feist 2009). This theory states that depressed people not only judge themselves harshly, but are also inclined to treat themselves badly because of their perceived shortcomings (in this instance, their inability to manage aggressive learner behaviour). The result is chronic misery, feelings of worthlessness, lack of purposefulness and pervasive depression (Feist and Feist 2009). The above theory is also in line with Beck's cognitive model of depression which emphasises that a depressed person systematically misevaluates ongoing and past experiences, leading to a view of the self as a loser (Pervin and Cervone 2010). Delfos (2004) agrees with the above theories, stating that intense feelings of unhappiness coupled with the negative behaviour of learners and teachers may be an indication that anxiety or depression is present.

Depressive episodes of the nature and severity experienced by the teachers often lead to severe stress and ill health, as revealed in this study. Feelings of worthlessness and hopelessness are usually accompanied by self-critical or negative thoughts which weaken the immune system, thereby increasing the individual's stress levels and rendering him/her vulnerable to illness (Coon and Mitterrer 2010).

\section{Stress and Ill-health}

There was agreement among the participants that learner violence had a negative impact on the victim's health. The principal of School D highlighted this problem with the following remark:

Every year I've got an educator ... one or two educators who will be on leave for 3-6 months. Now, therefore, this absenteeism, ill health among educators, ill health among the learners, it is becoming a problem. Most of my educators have become sickly; I don't have normal people anymore.

The principal of School E concurred with the above view as follows:

Once a teacher is stressed, definitely he's not going to perform very well. And that will involve many things as stress is accompanied by sickness ... Taking leave now and again; he's in today, tomorrow reporting sickness.

The reasons for the ill-health among teachers were raised by a teacher at School B:

There were occasions where educators were so de-motivated and depressed that psychological services had to be enlisted to try and help these educators to cope. Besides that ... people have been suffering from ill health.

Victims of aggressive acts often cannot cope with stress and may suffer from poor health because of their inability to cope with the harassment (Carter 2006; Rigby 2002). According to Pervin and Cervone (2010), the greater the reported levels of stress, the poorer the physical health will be and the greater the likelihood of psychological symptoms. The findings also concur with Bandura's social cognitive theory, which suggests that psychological stress depends 
on cognitions relating to the person and the environment (Lazarus in Pervin and Cervone 2010). According to this cognitive approach to stress and coping, stress is viewed as occurring when the person views circumstances as taxing or exceeding his/her resources and endangering well-being. Coon and Mitterer (2010) agree with the above theory by confirming that psychologists have now firmly established that stress affects health because stressful events reduce the body's natural defences against disease. Apart from the psychological trauma learner violence can instil in its victims, its consequences for learners, teachers and the school in general, can be serious. Research findings indicate that for every aggressive act there is a consequence, which adversely affects the individual concerned as well as the school and its community.

\section{The Consequences of Learner Aggression}

The findings revealed that the consequences of learner violence and aggression were many and varied. Victims of violence and aggression were absent from schools, indulged in drugs and alcohol abuse, became involved in vandalism in expressing their frustrations and helplessness, performed poorly academically and had suicidal tendencies.

\section{Absenteeism, Transfers and Resignations}

As mentioned previously, absenteeism was rife among the victims of learner violence. In a similar vein, the principal of School A confirmed the problem of absenteeism among learners and teachers alike:

Absenteeism happens among both learners and teachers after an act of aggression was witnessed ...the rate of absenteeism ... does increase because especially after a fight, with a blue-eye or a bruise on the face, learners tend to take days off. When somebody intervenes after a teacher has been humiliated by a child in class, the next possible thing that you normally see would be for the teacher to sob like a baby ... and it therefore becomes difficult the next day for the teacher to stand right up with your head held high in the same class where you were humiliated.

Learners at School D agreed that aggression and violence towards innocent teachers and learners had a definite effect on their attendance at school: "[T]he teacher will be afraid to come to school. It will also affect the attendance by students because they will be afraid to come to school."

Aggression and violence can have such a psychological and traumatic effect on the victims that they may actually ask to be transferred to another school. Moreover, frustration, anxiety and depression arising out of learner violence can drive teachers to tendering their resignation from the profession. As the principal of school $\mathrm{C}$ explained how learner aggression led to senior teachers resigning from the teaching profession:

There's the other teacher [who] ... resigned from the teaching fraternity - he took his package and went into business because he was frustrated with learner ill-discipline and learner violence in his school.

As the above findings suggest, learner violence and aggression caused absenteeism and career changes among teachers, with many resigning from the profession altogether. Dibetle (2008: 7) concurs by stating that teachers from rural and township schools are resigning from their jobs because they are the victims of psychological and physical violence perpetrated by learners.

The research findings confirm Steers and Rhodes's absenteeism model (Jacobs and Kritsonis 2007). This model emphasises that attendance is highly influenced by the practices of the organisation, an absence of a school culture, student attitudes and behaviour, values, and goals. On the same point, Bemak and Keys (2000) contend that prolonged absenteeism is detrimental to the learner's progress because he/ she falls further and further behind academically. Prolonged absenteeism on the part of both teachers and learners affects the learner's academic progress at school, which could lead to underachievement and even failure.

\section{Poor Performance}

Many participants indicated that one of the chief consequences of learner violence and aggression was poor performance of teachers and learners. Bemak and Keys (2000: 8) state the following: "Learners, who are victims of aggression, suffer psychological trauma, are concerned about their safety and are less able to 
concentrate and succeed academically." The principal of School A shared a similar view: "They don't perform well, that is both the teacher and the learner." In addition, a complaint was expressed by a learner at School B about the learners who had potential but were being deprived of quality instruction because of aggressive learners:

There are some learners who are very clever in class ... they are gifted ... they have got the brains to do things but when somebody who is aggressive in class ... puts them down when they do something [right] ... It will affect their [the victims'] performance in school.

The findings concur with the views of Bemak and Keys (2000), namely that being bullied in school leads to underachievement where the learners falls behind in assignments, homework and tests. The views of participants are in keeping with Bandura's social cognitive theory, which states that strong emotion ordinarily lowers performance - therefore, when people experience intense fear, acute anxiety or high levels of stress; they are likely to have lower efficacy expectancies (Feist and Feist 2009).

When the victims of violence and aggression absent themselves from school for long periods, this inevitably affects their performance in school. However, violent learners themselves become so frustrated with their inability to cope with the academic programme that they begin to vandalise the school property to vent their frustrations.

\section{Vandalism}

According to Moeller (2001), school vandalism levels are not only exceedingly high, but are still growing, as underscored by the findings of this study. A number of participants raised concerns about vandalism in their schools, as succinctly explained by the principal of School 5:

They [aggressive learners] would probably use anything they come across ... and vandalise the school in the process ... they become so uncontrollable that they would fight with anything they would come across and try and destroy everything that is in front of them because of this aggression, because of this bitterness.

Damaging buildings can be an expression of resisting authority (Delfos 2004). Another way for a youngster to express a sense of power and control is by damaging a building and defacing it with paint (graffiti) as the same principal explained: "This aggression that leads them to painting walls ... you know drawings that you wouldn't expect from a learner you know." The above findings support Dollard's frustration aggression theory that frustration produces aggressive energy, which activates violent and aggressive behaviour (Bandura 1973). This theory emphasises that if a person is frustrated, aggressive energy is created and transferred to material objects such as public symbols, which the aggressor regards as symbols of power, coldness and authority. Delfos (2004) agrees with this theory when he states that damaging school property can be an expression of resisting authority. Likewise, Finn and Frone (2003) confirm that both interpersonal aggression and vandalism at school were most likely to occur among learners with low levels of school identification and poor school achievement.

Importantly, the data confirmed that the victims of violence viewed the destructive nature of aggressive learners and their domineering attitude towards innocent teachers and learners with anger and bitterness.

\section{Anger and Bitterness}

Feelings of anger, frustration, resentment and hostility towards the attacker are but some of the physical symptoms experienced by the victims (Robbins 2000). The findings confirmed that teachers affected by violence displayed a deep sense of anger and bitterness towards their attackers. In this regard, a teacher (School B) expressed her frustrations as follows:

Psychologically we get so affected that it [ learner violence] also angers us ... it makes the educator aggressive and we do things that we not supposed to do, we engage in corporal punishment ... to hell with the law, take out the rod and give the child a couple of hits and he will sit down and keep quiet.

At the same time, learners who have been on the receiving end of violence from both violent teachers and learners reacted angrily to the violent acts inflicted upon them. As a student at School D stated: "The teacher will just maybe hit me. I will then ask myself: "What did I do wrong sir'? ... I will be angry with the teacher." It is the first time teachers are portrayed as perpetrators of violence, yet it is not uncommon for them to abuse their power. 
The above statements confirm Becks's cognitive theory of anger and related conditions (Olatunji and Lohr 2004: 1). The cognitive theory describes anger and bitterness as negative phenomenological experiences that exist on a continuum in which the frequency, intensity and duration of the experience, along with expressive characteristics, often lead to significant impairment. Deffenbacher et al. (2000) agree with the above findings by explaining that anger co-occurs with Type A behaviour as well as aggressive and sometimes violent behaviour on the part of the victims. Robbins (2000) expresses similar sentiments, namely that feelings of anger, frustration, resentment and hostility towards the aggressor are some of the physical symptoms experienced by the victims.

The victims of violence feel angry and bitter because of the violence inflicted upon them to the extent that some resort to suicide because of their highly depressed states.

\section{Suicide}

Depression is a psychiatric disorder accompanied by symptoms such as persistent feelings of hopelessness, and sometimes even suicidal tendencies. According to Shaffer and Kipp (2010), elevated levels of stress (of many kinds) are major contributors to the negative effects on adolescents who become seriously depressed. These learners are constantly in a state of depression and despondency and their depressed state may eventually lead to suicide. Evidence from the data revealed that learner violence in schools led to victims resorting to suicide because of their inability to cope with the constant humiliation and harassment meted out to them by their attackers. Accordingly, the principal of School A confirmed the incidence of suicide at his school arising from violence:

Some children ... would resort to suicide ... In the past two years we've had two cases of suicide and in the letters that the learners wrote ... they actually said that it was just too much for them.

The learners at School B also highlighted the effect of learner violence on victims to the extent that they resorted to taking their own lives. One student at School B substantiated this fact: "Aggression also causes learners to have low self-esteem ... and if they get depressed it can also lead to them committing suicide."
With the serious consequences of learner violence, victims became emotionally unstable and even resorted to suicide. The research findings confirm Durkheim's theory of suicide that views it as a phenomenon that arises from societal pressures and influences (Holmes and Holmes 2005). Coon and Mitterer (2010) validate this theory by asserting that the school community and family are major risk factors for suicide. Feelings of worthlessness, aggressive behaviour, shame, humiliation, failure or rejection racism and discrimination are all contributory factors to learner suicides. Moeller (2001: 55) concurs and points out that depressed learners exhibit signs of intense and pervasive unhappiness.

\section{CONCLUSION}

The aim of this study was to explain the impact of learner violence on learners and teachers. It also explained the consequences of such behaviour for all role players in rural secondary schools in the study. Irrespective of its origin, the study showed that the violence emanating from learner aggression has had catastrophic and dire consequences for victims who become depressed, lack self-esteem, dislike school, suffer anxiety and develop an array of psychological problems. It also showed the huge impact learner violence had on the quality of schooling and the harmonious relationships in the schools involved in the study.

The main limitation of the study is that the sample only included rural secondary schools that were previously categorised as Indian and Black schools. Since 1994, these Indian schools have opened their doors to other cultures too, in particular black learners. However, urban, independent and private schools were not part of the study and the findings cannot therefore be generalised to all schools. Hence studies that include other racial groups could reveal findings that differ from those described in this study. Nonetheless, this study provides a rich explanation of the experiences of principals, teachers and learners as regards learner aggression and violence in their schools. The potential solution to understanding schools afflicted with learner aggression and violence, could be unlocked by understanding the experiences of those individuals who face such acts of aggression in schools on a daily basis. 


\section{RECOMMENDATIONS}

Future studies could include comparative studies on learner violence and aggression in various school environments and survey studies which could include more schools that are representative of South African schools; studies that could explore the relationship between violence and educator discipline styles and studies to explore learners' experiences of violence in their schools. Another shortcoming of the study is that it focussed solely on learners as perpetrators of violence in schools when in reality there are other sources of school violence as well. The researchers trust that this study will provide a better understanding of the devastating effects of learner aggression and learner violence on innocent victims in rural secondary schools.

\section{REFERENCES}

Ancer J 2009. Steps to "Bully Proofing" a Child. Sunday Times, September 6, P. 7.

Anderson G 2007. The Impact of Bullying in the School on the Adolescent's Sense of the Self. Master's Dissertation, Unpublished. Pretoria: University of Pretoria.

Balt D 2008. The status of educators. Education Southern Africa: Lifelong Learning, 1(10): 8-10.

Bandura A 1973. Aggression: A Social Learning Analysis. Englewood Cliffs, NJ: Prentice-Hall.

Bemak F, Keys S 2000. Violent and Aggressive Youth: Intervention and Prevention Strategies in Changing Times. Thousand Oaks, CA: Corwin Press.

Bester S, Du Plessis A 2010. Exploring a secondary school educator's experiences of school violence: A case study. South African Journal of Education, 30(2): 203-229.

Blaser T 2008. School safety influences literacy rate. SAIRR Today, 2(14): 1

Carter C 2006. School Violence Cuts Across Race and Class Lines. Sunday Tribune, July 30, P. 27.

Coon D, Mitterer JO 2010. Introduction to Psychology: Gateways to Mind and Behaviour. $12^{\text {th }}$ Edition. Belmont, CA: Wadsworth.

Delfos MF 2004. Children and Behavioural Problems: A Biopsychological Model with Guidelines for Diagnostics and Treatment. London: Jessica Kingsley.

Deffenbacher JI, Huff ME, Lynch RS, Oetting E, Natalie F 2000. Characteristics and treatment of high-anger drivers. Journal of Counselling Psychology, 47: 5-17.

Dellasega C, Nixon C 2003. Girl Wars: 12 Strategies that will End Female Bullying. New York: Simon and Shuster.

Dibetle M 2008. When school isn't safe. The Teacher, 13(4): $5-7$.

Du S, Jaaniste T, Champion DG, Yap SL 2008. Theories of fear acquisition: The development of needles phobia in children. Journal of Pediatrics, 10(2): 13-15.

Feist J, Feist GJ 2009. Theories of Personality. $7^{\text {th }}$ Edition. New York: McGraw-Hill.

Finn KV, Frone MR 2003. Predictors of aggression at school: The effect of school-related alcohol use. NASSP Bulletin, 87(636): 38.
Gasa V 2012. Exploring the relationship between learners' aggressive behaviour and disrupted family life. Anthropologist, 14(3): 199-207.

Holmes RM, Holmes ST 2005. Suicide: Theory, Practice, and Investigation. Thousand Oaks, CA: Sage.

Jacobs KD, Kritsonis WA 2007. An Analysis of Teacher and Student Absenteeism in Urban Schools: What the Research says and Recommendations for Educational Leaders. The Lamar University Electronic Journal and Student Research. From <www.nationalforum.com.> (Retrieved February 23, 2012).

Jenson JM, Dieterich WA 2009. Preventing Childhood Aggression and Bullying: Implications for Schoolbased Intervention. Graduate School of Social Work, Denver, Colorado.

Johnson B, Christensen L 2011. Educational Research: Quantitative, Qualitative, and Mixed Approaches. $4^{\text {th }}$ Edition. Thousand Oaks, CA: Sage.

Mabitla MA 2006. Causes and Manifestations of Learner Aggression among Secondary School Learners. Doctoral Thesis, Unpublished. Pretoria: University of South Africa.

Makwabe B 2007. Teachers Under Siege. Sunday Times, September 9, P. 4

Marsh L, Williams S, McGee R 2009. Teacher's perception of physical aggression among secondary students: ANew Zealand view. Australian Journal of Education, 53(3): 245-250.

McDermott R 2006. Testosterone, Cortisol and Aggression in a Simulated Crisis Game. From < http: //digitalcommons. unl.edu/politicalsciencehendricks $/ 5>$ (Retrieved March 3, 2011).

McMillan JH, Schumacher S 2006. Research in Education: Evidence-based Inquiry. $6^{\text {th }}$ Edition. Boston, MA: Pearson Education.

Moeller TG 2001. Youth Aggression and Violence: A Psychological Approach. Mahwah, NJ: Lawrence Erlbaum Associates.

Myburgh C, Poggenpoel M 2009. Meta-synthesis on students' experience of aggression in secondary schools in South Africa. South African Journal of Education, 29(4): 445460.

Naran J 2006. Learning Fear at School. Tribune Herald News, 8 October, P. 8.

Olatunji BO, Lohr JM 2004. Non-specific factors and the efficacy of psychosocial treatments for anger. Journal of Clinical Psychology, Psychiatry, and Social Work, 3(2): $1-22$.

Pervin LA, Cervone D 2010. Personality Theory and Research. $11^{\text {th }}$ Edition. Hoboken, NJ: Wiley.

Poggenpoel M 1998. Data analysis in qualitative research. In: AS De Vos, H Strydom, CB Fouche, M Poggenpoel, EW Schurink (Eds.): Research at Grass Roots: A Primer for the Caring Profession. Pretoria: Van Schaik: pp. 334-353.

Rigby K 2002. New Perspectives on Bullying. Philadelphia and London: Jessica Kingsley.

Robbins PR 2000. Anger, Aggression and Violence. Mahwah, NJ: Lawrence Erlbaum Associates.

Shaffer DR, Kipp K 2010. Developmental Psychology: Childhood and Adolescence. $8^{\text {th }}$ Edition. Belmont, CA: Wadsworth

Singh GD 2012. Managing Learner Aggression in Rural Secondary Schools in the Empangeni District of Kwazulu-Natal. M Ed Dissertation. Unisa.

Smit ME 2003. The bully/victim problem in South African primary schools. Acta Criminologica, 16(4): 27-33.

Weingarten K 2003. Common Shock: Witnessing Violence Everyday: Wow We Are Harmed, How We Can Heal. New York: Penguin. 